\title{
“-VENID, MOCHACHOS, Y VERÉIS EL ASNO DE SANCHO PANZA..."
}

\author{
" $[$... ] ho considerato che la materia asi- \\ nale, essendo infinita, mi è rimasta alcuna cosa \\ de la qual possa parlarvi ancor io come a cosa \\ nova". \\ Grovan Battista Pino, Ragionamento soura \\ del asino, 1551-1552. \\ " [. . . ]ió no intendo vera- e seriosamen- \\ te lodar l'asino e l'asinitade, ma più tosto pro- \\ curo di aggionger oglio a quella lucerna la qua- \\ le è stata da gli altri accesa". \\ Gtordano Bruno, Cabala del cavallo pegaseo \\ 1585 .
}

$\mathrm{Al}$ amparo de las dos autoridades citadas en epígrafe, y de la tupida tradición que los respalda y les sucede, me atrevo a entrar en tema no poco arriesgado por más de un motivo que dejo a la fácil intuición del lector, al cual pido benevolencia ante este probable desacierto. Grande fue, al contrario, el acierto de quien eligió y perfiló la cabalgadura del escudero, como fervorosamente quiso subrayar hace más de un siglo uno de los tantos admiradores del cuadrúpedo que nos ocupará y de la novela en la que se mueve, el literato y patriota Francesco Domenico Guerrazzi:

Michele Cervantes Saavedra, lepido romanziere quanto prode soldato di Spagna, studiando assegnare a Sancio Pancia, vera perla degli scudieri fedeli, una cavalcatura degna di lui sia nella lealtà, sia nel giudizio, poiché si ebbe guardato un pezzo dintorno, non seppe eleggere Bestia che per ogni rispetto gli si adattasse meglio dell'Asino; e il savio Ibero di così onesti (e se non mel vietasse modestia, direi santi) costumi, di così saggia ed illibata vita si piace pre-

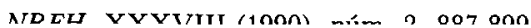


sentarmi fornito ai lettori, che questi pendono tuttora incerti a distinguere, quali dei tre eroi celebrati da lui egli intendesse onorare maggiormente o Don Chisotto o Sancio Pancia o l'Asino'.

Algo exagera Guerrazzi, aunque le excuse el haber puesto el elogio directamente en boca de un ejemplar de la especie interesada. Pero es verdad que nunca al rucio de Sancho le han faltado bocas y plumas humanas dispuestas a tejer sus elogios e incluso a apuntar a su alrededor alguna nota de crítica y erudición, compartida casi siempre con Rocinante, al cual le vinculaba celebrada fraternal amistad, garantía contra la envidia. En años recientes ambos han sostenido gallardamente el escudriño y el peso de una tesis doctoral, que ha investigado su "raza, capa, alzada, edad, sexualidad, condición, tipo funcional, marchas, defectos o tachas, utilización y valoración", hasta delinear una "posible biografía de cada uno de los semovientes" y sus "respectivas etopeyas"'2. Es evidente que por esta ladera ya no queda espacio para inquirir y profundizar más. Mínimo parece el lugar todavía disponible por la ladera crítico-descriptiva de actitudes y papeles de estos dos personajes en función de los amos y de sus desventuras y venturas dentro de la invención novelesca. Es cierto que en el casi constante emparejamiento sale favorecida la cabalgadura del "señor de la historia", mientras a la de su escudero la atención parece dedicada más bien por un gusto de simetría y por impulsos de simpatía, desde luego sinceros pero que no ocultan del todo el convencimiento de que, en el fondo, el anónimo rucio es poco más que un paciente corpezuelo sin asperezas que ofrecer a las garras de la exégesis. Entre las típicas ligerezas de la crítica, no será ésta la que pueda merecer la palma del escándalo; pero cualquier buen lector de la novela cervantina y admirador incluso modesto del jumento de Sancho no puede permanecer indiferente ante el manifiesto agravio que a tal critatura - y al " padrastro" - se le hace cuando se afirma que "no presenta problemas ni contrastes", $y$ esto en un cuidadoso ensayo monográfico ${ }^{3}$.

${ }^{1}$ F. D. Guerrazzi, L'asino. Sogno, introd. e note di Zino Zini, UTET, Torino, 1928, t. 2, p. 35.

${ }^{2}$ Lamento no haber podido consultar esta tesis, que se ha publicado: Las cabalgaduras de Don Quijote y de Sancho, Heraldo de Zamora, Zamora, 1976. De ella da noticia y sumario el autor, el doctor veterinario Justino Pollos HERRERA, "Rocinante y el rucio en el Quijote de Avellaneda", CICer, 837-855.

${ }^{3}$ MonTSERRAT ORdóñez Villa, "Rocinante y el asno, personajes cervantinos", Razón y Fábula, Bogotá, 1968, núm. 8, 57-65, esp. p. 62. 
Respetando el temperamento pacífico de nuestro sujeto, enemigo de arrancadas, emprenderemos con él y en el teatro de sus empresas un recorrido que será demorado y paciente como al asnal compañero conviene, y como él, quizás, un tanto divagante.

Reconozcamos que el panorama que la Primera parte del Quijote presenta a nuestro particular punto de observación justifica en pleno el parecer de la monografía antes citada. La situación de mayor envergadura que el asno protagoniza, el famoso robo, cae exclusivamente dentro de la problemática de la composición, incluso tipográfica, de la novela ${ }^{4}$. Los dos segmentos a ella relativos, saltados y recuperados o añadidos, glosan con gracia una serie de lugares comunes del motivo de la entrañable unión del villano con su asno, según una fraseología y un énfasis cómicos de cortos vuelos. Si no queremos resignarnos a lo insustancial de tales segmentos, sólo de un par de sus frases podríamos exprimir algún jugo, e incierto, relacionado con otra clase de tópicos asnales y antivillanescos de larga tradición. Al apelar Sancho al asno "hijo de mis entrañas", percibimos una resonancia de la injuriosa atribución al villano de la misma sustancia y naturaleza del burro, hijos ambos de la tierra y el uno del otro. El piropo "regalo de mi mujer", dicho sea con perdón de la castísima señora de Panza y de todos (?) los lectores del Quijote, podría ser menos inocente de lo que parece: solía exaltarse la virilidad paladina del asno, símbolo de fecundidad grato a villanas y señoras en más de una pieza cómica; y sería tentador sacar a colación el empeño de la Duquesa: "quédese a mi cargo el regalo del rucio"' (II, 33, p. 303), sabiendo cuán sutiles e imprevisibles son las vías cervantinas de la ambigüedad y de la malicia. Pero nos ataja este mal sendero Sancho en persona con un "mi regalo", referido al asno una vez

\footnotetext{
${ }^{4}$ Remito solamente a Daniel Eisenberg, "El rucio de Sancho y la fecha de composición de la segunda parte de Don Quijote", NRFH, 25 (1976), 94102; y la ed. de Vicente Gaos de Don Quijote de la Mancha, Gredos, Madrid, 1987 , t. 3, pp. 218-227, donde se expresan y discuten numerosas dudas pero no se rechaza del todo la opinión mayoritaria que aboga por la autenticidad, ya que "con Cervantes nunca se puede estar seguro de nada" (p. 227), que sería buen lema para varios de estos apuntes míos. Me adhiero al parecer de la mayoría. Mis citas del Quijote remiten a la ed. de LuIs A. Murillo, Castalia, Madrid, 1987, 2 ts. Algún punto de los tocados aquí lo he rozado, dentro de otros contextos, en: "La nobildonna e le dilettevoli trasgressioni dello scudiero: Sancho Panza alla corte dei Duchi', I codici della trasgressività in area ispanica, Verona, 1980, pp. 53-62; 'Panico e rivalsa: Sancho Panza nell'avventura delle gualchuere (Quijote, I, 20)”, 'HFM, 153-170.
} 
más, que es ajeno a cualquier insinuación, e informándonos que a su rucio "no le tocaban las generales de enamorado" (I, 25, p. 308). Confirma lo descaminados que estábamos la docta tesis doctoral antes citada, en la que se da como muy verosímil una condición de castrado de nuestro imperturbable semoviente ${ }^{5}$. Por lo tanto la intrascendencia de sus apariciones en la Primera parte no presenta fisuras. Sancho "doquiera que vía asnos se le iban los ojos y el alma" (I, 30, p. 380 n.) y Teresa pide noticias de la salud del asno antes que de la de su esposo cuando los dos "héroes" regresan (I, 52, p. 602): teniendo como lema estas dos apuntaciones, todo el tratamiento del motivo asnal en el primer Quijote cae bajo el signo de la más obvia y trillada tradición de este aspecto del tema villanesco teatral y narrativo.

Sin embargo, el fuego vital que rescata al dinámico personaje Sancho del más bien estático tipo tradicional en que hunde sus raíces, suelta una chispa que toca al rucio, o mejor dicho a la relación que une al asno con su amo, la cual participa de algunos reflejos de aquel proceso de maduración y afinamiento que distingue al escudero en sus actitudes hacia el mundo exterior y sobre todo hacia su propia persona y naturaleza. El tópico de la asnofilia villanesca, confiado en general a manifestaciones bastante ramplonas y asistemáticas, es objeto a lo largo de nuestra novela tanto de un ahondamiento y una depuración en sus motivaciones afectivas como de un enriquecimiento de su substrato cultural y folklórico. En este segundo aspecto probablemente sin que el autor tuviera siempre plena conciencia de ello.

$\mathrm{El}$ asno entra en escena impuesto por la necesidad (y por los proverbios, dirían los anotadores: "Allá va Sancho con su rocín", etc.), siendo la única cabalgadura disponible para Sancho en el momento, pero destinado por Don Quijote a una inmediata sustitución con el primer caballo conquistado al primer adversario (I, 7, p. 126). Sancho no manifiesta opinión contraria y, cuando ve llegada la ocasión del cambio con la derrota del barbero, se sorprende y protesta por la prohibición de Don Quijote; en el fondo, se trataba de "trocar un asno por otro", como el mismo Sancho debe admitir (I, 21, pp. 256-257). Pero de ahora en adelante no se volverá ya a contemplar la eventualidad de una separación del rucio que no sea la forzada a consecuencia de su robo. Ese sorprendente y dolorido evento parece revelar a Sancho no sólo lo imprescindible que era el auxilio material prestado por el animal,

${ }^{5}$ Justino Pollos Herrera, art. cit., p. 844. 
sino también el firme lugar que en sus afectos ocupa su rucio. Esta singularidad y su gratificación para el escudero se van construyendo en la Primera parte; le toca a la Segunda explayar su apoteosis. La cual se estrena con la rotunda afirmación de Sancho que su rucio "vale dos veces más que el caballo" de Don Quijote con "cuatro fanegas de cebada encima" (II, 13, p. 129); valoración que no andaba del todo descabellada, como quizás la sucesiva, cuando es nada menos que "el rocín del señor Lanzarote" el indigno de sustituir al rucio (II, 31, p. 275). Su compañía satisface tanto al escudero que no cambiaría su condición ni con la del más poderoso señor de los infieles, el Gran Turco (II, 36, p. 322), ni con la del más representativo señor de los cristianos, el Emperador de Alemaña (II, 44, p. 368). La grotesca felicidad del villano con su animal, del villano-animal, condensa en las hipérboles un elemental "menosprecio de corte" (temprano aviso hubo durante la cena con los pastores: I, 11, p. 154) y un no menos burdo regodeo de autorrealización, recursos ambos de una comicidad superficial. Pero en el contexto de nuestra novela el recurso sale de la rutina gracias a su función. Frente al bien equipado escudero del Caballero del Bosque, Sancho pone reparo a su complejo de inferioridad de caballero asnal colocando su cuadrúpedo por encima del de su $\mathrm{amo}^{6}$. En el castillo de los duques y delante de doña Rodríguez el escudero propone su manera particular de vivir un modelo y ensaya la consagración de su identidad adquirida pretendiendo respeto hacia su cabalgadura; y esto aparte de todos los humores paródicos y socarrones de nuestro sujeto y de su "padrastro". El Gran Turco es evocado en la reso-

${ }^{6} \mathrm{Al}$ mismo tiempo rescata al individuo rucio de la tradicional sujeción que la especie asnal padece respecto a la equina. El rucio y Rocinante por su cuenta habían anulado ya la milenaria oposición entre las dos familias al calor de un recíproco cariño, tan ejemplar frente a los rencillosos humanos que había merecido una definición más propia de relaciones entre personas: es la fórmula "bue amor y compañía" que define lo que alegraba los corazones de los dos cuadrúpedos (I, 21, p. 257), como - por ejemplo - fue "mucho amor y buena compañía" lo que unía a doña Catalina de Salazar con su marido don Miguel, según declara ella en un temprano (1610) testamento (CRISTÓ. Bal PÉrez Pastor, Documentos cervantinos hasta ahora inéditos, Madrid, 1897, t. 1, p. 161). Como propia del "bajo vulgo" anota tal fórmula Francisco RoDríguez Marín en su ed. a Don Quijote, Madrid, 1948, t. 5, p. 161 y t. 7, pp. 96-97. Otra fórmula encarece irónicamente el vínculo entre Sancho y el asno: "amistad y buena fe" (II, 34, p. 306); y "en buena paz y compañía" habían consumido su primera cena juntos el caballero y el escudero (I, 10, p. 153). 
nante e hiperbólica garantía que Sancho da por carta a Teresa de no olvidarse nunca del preciado rucio. En el Emperador de Alemaña, en fin, se cifra un máximo de fastuosidad y poder, el mismo que - dentro de su perspectiva e historia personal- Sancho piensa haber alcanzado en el momento en que se encamina, rodeado de todas las señas de la autoridad y de la magnificencia, hacia su exaltante prueba de gobierno. En los cuatro casos es superada la extremosidad gratuita de la cual se complace una mente primitiva: la hipérbole da énfasis al amor propio ante un " $c 0-$ lega" en apariencia más afortunado, al gusto de ejercer un derecho deparado por la convención caballeresca, al cariño que previene y se propone anular una segura preocupación de la mujer y al entusiasmo por el sueño que se realiza. Lo elemental de las expresiones no es caricatura, o no quiere ser sólo caricatura; manifiesta recovecos íntimos del ánimo de Sancho y patentiza un sistema lingüístico-conceptual típico de una cultura rústica, que no equivale a decir rudimentaria.

La intimidad de Sancho con el rucio nunca responde a la vulgar "asnificación del villano" - en palabras de Salomon-, corriente en el teatro anterior y contemporáneo de Cervantes ${ }^{7}$, bien conocida por él y de la que tantos recursos aprovecha. Veamos un caso característico de adopción plena y de sucesiva meridiana superación. "Asno eres - le grita Don Quijote a Sancho en uno de los raros pero fuertes momentos de ira contra el escudero-, $y$ asno has de ser, y en asno has de parar cuando se te acabe el curso de la vida"; definición y profecía que tienen el consentimiento completo del interesado: "Señor mío —contesta en efecto Sancho-, yo confieso que para ser del todo asno no me falta más de la cola; si vuestra merced quiere ponérmela, yo la daré por bien puesta, y le serviré como jumento todos los días que quedan de mi vida" (II, 28, p. 260). La "asnificación" no puede ser más explícita y radical, hasta brutal; todo lo contrario de la maliciosa alusividad del duque, un poco después: "descuide Sancho, que se le tratará [al asno] como a su misma persona" (II, 31, p. 276). Más adelante la historia depara a nuestro escudero una circunstancia que por poco no da cumplimiento a la profecía del amo,

7 NöEl Salomon, Recherches sur le thème paysan dans la "comedia" au temps de Lope de Vega, Université de Bordeaux, Bordeaux, 1965, p. 12; Castalia, Madrid, 1985, pp. 25-26; Francisco Márquez VillanueVa, Fuentes literarias cervantinas, Gredos, Madrid, 1973, pp. 43 y 63; cf. también MAURICIO MolHo, Cervantes: raiees folklóricas, Gredos, Madrid, 1976, p. 237. 
por cierto no en cuanto a la metamorfosis de Sancho sino por encontrarse éste en condición muy cercana a la conclusión del "curso de $s u$ vida" y además en estrechísimo contacto con su rucio, casi un solo cuerpo. Es cuando ambos caen "en una honda y escurísima sima" y la desesperación lleva a Sancho a imaginar la próxima muerte suya y del asno y a ver ya sus huesos " mondos, blancos y roídos", mezclados los de la bestia con los del hombre; pero esa unión atestiguará después de la muerte la indisolubilidad de la pareja, y la fama que de ella corre permitirá la identificación de los que fueron cuerpos y seres vivos. Los restos del rucio recobrarán así una identidad para los de Sancho y los de Sancho se la darán a los despojos del animal. La unicidad de un lazo y de un cariño celebrará su triunfo, considera Sancho entre lamentos (II, 55, pp. 454 ss.). Es probable que más de un lector se haya conmovido y siga conmoviéndose con Sancho ante ese lazo y ese cariño. Igualmente probable, o quizás más, es que otros lectores se hayan reído y sigan riéndose; y con el mismo derecho del que se enternece, porque en ambos efectos pensó seguramente el narrador y puede que incluso él mismo haya sentido ambos. Aunque conociendo de qué parte suele cojear el "segundo autor" de la historia, me inclino a presumir que fuera más risa que ternura lo que él sintió e imaginó que sentirían los lectores. E imaginando a su público, como era su costumbre, por agudo que él siempre fuera no podía trasladarse mucho más allá de su época, cuando la risa frente al episodio y a las reflexiones aludidas debía de teñirse inevitablemente con los colores fuertes del tópico antivillanesco del hombre-bestia. ¿Qué figura podía representar mejor el machacado motivo de la consubstancialidad de labrador-asnotierra que ese pérfido cuadro de Sancho y su burro tragados por la campaña que absorberá sus humores y cuerpos, y de la contemplación del cúmulo de huesos cuya identificación favorecerá más a la bestia que al humano? Procediendo hacia adelante en las páginas, y en el subsuelo, encontraremos confirmaciones; pero alguna podemos recuperarla dando un paso atrás y precisamente en el punto de la despedida de Barataria, allí donde (II, 53, p. 444) el camino hacia "la vida pasada", o sea hacia la autenticidad, se abre con el "beso de paz" que Sancho da en la frente a su rucio, al que había abandonado y olvidado para montar "sobre un macho a la :jineta' (II, 44, p. 368), y quiere dirigirse -ese camino- a las tareas de "arar y cavar, podar y ensarmentar las viñas"': asno, tierra y viña son los elementos gracias a los cuales el villano piensa y puede "resucitar de la muerte presente" de 
una descabellada enajenación, recobrando su universo genuino y recomponiendo así la unidad primigenia ${ }^{8}$. Cada uno de estos motivos es un muy gustado lugar común; no lo es su distribución y enlace, y el conjunto resulta fuertemente semantizado y sugestivamente simbólico.

Una vez recompuesto el vínculo con el animal, la caída en la sima y la traumática experiencia en las entrañas de la tierra completan el reencuentro de Sancho consigo mismo, pero como algo más que una "purgación necesaria y simbólica" -en justas palabras de Casalduero ${ }^{9}$ : es la reintegración material del labradorasno con una madre que a esta centáurica criatura se atribuía con sentidos y humores mucho menos benévolos que para los demás seres. Es también una "bajada a los infiernos", según otra definición de Casalduero, pero no para cerrar la aventura de Barataria y concluir su sentido. La caída es la vía que marca una vuelta simbólica a la renovada antigua vida, la recuperación del pacto originario como lo había sido el beso al asno.

Sin embargo, la intuición de los infiernos tiene una vigencia en otra dirección, en la que volvemos a encontrar al fatídico animal. El asno en antiguas mitologías iba asociado a divinidades del subsuelo y participaba de sus atributos negativos de muerte, pero también del poder generador de nueva vida albergado en el vientre de la tierra, con la obvia coincidencia entre principio de muerte y principio de vida. Los dos principios presiden a la estancia subterránea de Sancho, que protagoniza una simbólica experiencia de muerte y de resurrección, un rito entre purificador

${ }^{8}$ Augustin Redondo, "Tradición carnavalesca y creación literaria. Del personaje de Sancho Panza al episodio de la ínsula Barataria en el Quijote", $B H i, 80$ (1978), 39-70, apunta agudamente que la ausencia del burro en los días de la Barataria es una de las señales de la momentánea inversión en la naturaleza de Sancho.

9 Joaquín Casalduero, Sentido y forma del "Quijote" (1605-1615), Ínsula, Madrid, 1975, p. 343. Afín la interpretación de Helena Percas De Ponseti, Cervantes y su concepto del arte. Estudio crítico de algunos aspectos y episodios del "Quijote", Gredos, Madrid, 1975, t. 2, pp. 630-637. El paralelismo existente entre la sima y la cueva de Montesinos hacen apropiadas para nuestro episodio muchas de las consideraciones de AUgustin REDONDo, "El proceso iniciático en el episodio de la cueva de Montesinos del Quijote", I, 1981, núm. 13, 47-61; cf. también Piero Camporesi, Il paese della fame, Mulino, Bologna, 1978, p. 37: "Il viaggio esoterico e purificatore si configura anche come discesa verso il «basso", come regressio ad.uterum [...], dentro la grotta, il sotterraneo caldo [...] L'itinerarium in ventrem [...] è anche un ritorno alle origini, un viaggio verso il centro e le viscere della terra"'. 
e iniciático, cuyo fin no debe ser tanto el exordio hacia lo nuevo sino más bien la recuperación de lo auténtico. En la fase final menudean expresiones como "la otra vida", donde Sancho cree estar ya, o "enterrado en vida", "muerto", "penando su alma", etc. (II, 55, pp. 457-458). Para marcar la conclusión real y simbólica del oscuro y regenerador itinerario y para atestiguar la identidad del escudero a los oídos de un incrédulo Don Quijote, llegará justamente el familiar rebuzno del rucio, esa elocuente sonoridad grata a tantas plumas festivas y nada despreciada por la de nuestro narrador ${ }^{10}$.

Que la pluma de nuestro narrador sea esencialmente festiva es indudable. Dudoso puede volverse entonces el detectar tanto simbolismo y cruce de sentidos profundos en el manejo de un villano, un asno, una sima y un rebuzno. En efecto, en las páginas comentadas y en otras que comentaré, más que una evidente construcción sistemática y elaborada se observa el aflorar como casual y despreocupado de elementos, sueltos o agrupados, que la cultura colectiva había dotado de una semántica enriquecida e injertado en una red de relaciones fijas que los ha vuelto emblemáticos, figuras alusivas que siguen viajando en la memoria y en la vida de la colectividad, o ya como simples fantasmas y supervivencias formales o todavía como letras de un alfabeto segundo. Abundan en nuestra novela y su ambigüedad intrínseca celebra la inevitable alianza con la ambigüedad del narrador, que es a todas luces un ingenio tan festivo como despistador. Así que lo más prudente es moverse casi como arqueólogos, y trasnochados además, rastreando y sugiriendo identificaciones sueltas, sin acentuar osadas reconstrucciones y sin contar a la fuerza con una intencionalidad del artífice, el cual en más de un caso pudo ser

${ }^{10}$ Remiten por supuesto estas palabras a aquel magistral ejemplo de relaboración de materiales folklóricos que son las páginas de II, 25, verdadera apoteosis del rebuzno (que tiene en Sancho un campeón: II, 27, p. 255) y de la asnalidad villanesca. Comentario adecuado pueden ser estos renglones de Piero Camporesi, La maschera di Bertoldo. G. C. Croce e la letteratura carnevalesca, Einaudi, Torino, 1976, p. 68: “"Prima che fossi tu, né manco la tua corte - esclama trionfalmente Bertoldo all'indirizzo di Alboino-, l'asino aveva ragliato quattro mili' anni innanzi». Il tempo degli uomini e della storia viene mortificato (insieme all'orgoglio dei potenti) da una durata diversa [ . . ] Il raglio del "risonante" è più forte delle trombe dei conquérants e dei loro confusi e inutili rumori d'armi, come la ineluttabile continuità delle stagioni e del lavoro dei figli della terra e dell'asino-pater è più forte degli effimeri accidenti escogitati dalla transitoria storia degli uomini sulle vicende eterne della natura". 
simplemente el involuntario testigo de una imagen que llevaba grabada en su retina, real o metafórica, y que ya ninguna comunicación tenía con zonas y órganos más internos y complejos. ¿Qué tema más festivo que el del asno para jugar y divertir sin trascendencias? ¿Cómo es posible complicar criatura tan simple y angelical como el rucio de Sancho asociándolo con el Infierno? El primero en protestar es el mismo rucio, respaldado por Sancho y Don Quijote, cuando el narrador osa cargar en sus lomos nada menos que el Diablo en persona, o casi. Es uno de los farsantes de la compañía de Angulo el Malo, como se recordará, quien se lleva al rucio; y a Sancho que se queja a Don Quijote: "el Diablo se ha llevado al rucio", el caballero asegura: "yo le cobraré $[\ldots]$, si bien se encerrase con él en los más hondos y escuros calabozos del infierno" (II, 11, p. 118). La asociación es explícita y cumplida, como seguros los efectos cómicos del episodio, que bien pudo ser una inocente invención, aunque es oportuno tener siempre presente que la inocencia del narrador es la figura retórica señera de nuestra gran novela. Era una invención que - lo supiera él o no - pescaba en el extenso piélago del patrimonio folklórico y a él guiñaba el ojo, lo quisiera él o no. Como seguramente lo guiñaba ese farsante-diablo que "en la punta de un palo traía tres vejigas de vaca hinchadas" y que "saltó sobre el rucio, y sacudiéndole con ellas, el miedo y el ruido, más que el dolor de los golpes le hizo volar por la campaña". Muy otros los guiños de Sancho: "cada vez que veía levantar las vejigas en el aire y caer sobre las ancas de su rucio eran para él tártagos y sustos de muerte, y antes quisiera que aquellos golpes se los dieran a él en las niñas de los ojos que en el más mínimo pelo de la cola de su asno" (id). La cual era una manera de decir, pues más adelante nuestro Sancho afirmará que bien habría preferido que Amor descargara sobre el rucio los martirios que a él le tocaba sufrir para "resucitar" a Altisidora (II, 70, p. 565). Pero no es el tambaleante altruismo del escudero lo que interesa aquí, sino elementos como las vejigas, el animal golpeado por ellas y que corre asustado, la referencia a su rabo, que componen una escena carnavalesca del tipo apuntado por Correas en el exordio de una de las glosas de su Vocabulario de refranes: "Por Antruejo atan vejigas hinchadas a la cola a los perros [...]", bien ilustrada por las investigaciones de Caro Baroja ${ }^{11}$.

11 Julio Caro Baroja, El Camaval. (Análisis histórico-cultural), Taurus, Madrid, 1965 , pp. 53 ss., $60,111,206,358,361$ y 364 sobre figuras carnavalescas 
Del Infierno al Carnaval y a la "locura": tres universos muy emparentados y los tres muy familiares al más receptivo y ecuménico de los animales, al asno. Menos lo eran a nuestro rucio, criatura casera mimada por los Panza y puesta a duras pruebas por un sádico narrador. Para el rucio nada significa ya que ese imprevisto e incómodo caballero sea o represente por un lado un arcaico y mítico compadre de su especie y por otro lado actúe encima de sus lomos como otro más reciente compañero, el "loco" bufonesco, que la tradicion había acabaclo vinculando al animal tan íntimamente que de su caperuza quería que siempre asomara el más vistoso de los atributos asnales, el soberbio par de orejas ${ }^{12}$. $Y$ que hacia esa parte tirara el demomo que cabalga al rucio no hay dudas: "venía vestido de bogiganga, con muchos cascabeles [...] el cual moharracho, llegándose a Don Quijote, comenzó a esgrimir el palo y a sacudir el suelo con las vejigas, y a dar grandes saltos, sonando los cascabeles", como el típico "loco" carnavalesco que era ${ }^{13}$.

Pero el tal moharracho no es el solo y momentáneo "loco" cuyo peso debe soportar el rucio. Otro le ha tocado para la vida, aunque totalmente pacífico. Es su dueño, Sancho Panza en per-

equipadas con vejigas (llamadas dimons en zonas de Cataluña, p. 364); cf. además A. Redondo, "Tradición...", p. 48, y la ed. cit. del Quijote de Rodríguez Marín, t. 4, p. 245, n. 1. Sin querer caer en la más mínima faita de respeto al rabo del rucio y sin dudar de la honestidad de Sancho, recuerdo muy de paso que la cola del asno era figura de su vigor fálico. Que lo fuera cualquier rabo bien muestra saberlo y saborearlo nuestro narrador por boca de una ventera (I, 32, p. 392); que mejor cuadrara con el del asno, símbolo de la fecundidad, bien lo implican -entre otros - un par de grabados quizás dürerianos de La nave de los locos de Sebastian Brant (trad. italiana, a cura di Francesco Saba Sardi, Spirali, Milano, 1984, caps. 35 y 64: una mujer se agarra al rabo de un asno cabalgado por un "loco"; el cap. 64 atañe a la lujuria femenina. La Narren schyff apareció en Basilea en 1494 y circuló sobre todo a través de la libre traducción en latín Stultifera navis de Jacob Locher, impresa tres años después siempre en Basilea). Véase también el "caudam monialibus"' en el reparto que de su propio cuerpo hace el animal en el tradicional testamento: GiUSEPPE SCALIA, "Il Testamentum asini e il lamento della lepre. Redazioni nuove", StM, 1 (1962), 129-161, en esp. pp. 133 y 135. Sobre cola y ventera cî. ed. cit. del Quijote por Rodríguez Marín, t. 3, p. 8, n. 7.

${ }^{12}$ Cf. como ejemplo todos los grados de Narren Schuyff.

${ }^{13}$ Cf. el comentario a este pasaje en J. Caro Baroja; op. cit., p. 122 y ta ed. del Quijote de Luis A. Murillo, t. 2, p. 117; también A. Redondo, "Tradición...", p. 48, y P. CAMPOREsı, Il paese..., pp. 28 y 33. el cap. $110 \mathrm{~b}$ de Narren schyff es relativo a "locos" y "locuras" en Cuaresma y a cierto protagonista asnino. 
sona, "loco" constante por dentro, "loco" intermitente por fuera, como cuando "vestido a lo letrado, y encima un gabán muy ancho de chamelote de aguas leonados, con una montera de lo mesmo, sobre un macho a la jineta', procede regocijándose a la vista de su rucio que le sigue adobado "con jaeces y ornamentos jumentiles de seda y flamantes" (II, 44, p. 368) ${ }^{14}$; o como cuando, poco tiempo antes, al salir de caza con los duques exhibe un vestido "verde, de finísimo paño" y va orgulloso "encima de su rucio, que no le quiso dejar, aunque le daban un caballo" (II, 34, p. 305). Después de los buceos de Márquez Villanueva sabemos a qué apunta el color de ese traje de Sancho, como se lo sabían y gustaban los duques que se lo habían destinado ${ }^{15}$. En los dos momentos en que Sancho lleva ambiguos indumentos el asno está a la vista o va debajo de él. En una tercera ocasión el mismo paño lo ensayarán ambos, por separado.

Con esa ocasión llegamos al final de la novela y de este recorrido. Regresan al pueblo el que ya fue caballero y el que no podrá ser ya más escudero. El rucio avanza llevando a cuestas "el lío de las armas" y encima "la túnica de bocací pintada de llamas de fuego que le [a Sancho] vistieron en el castillo del duque la noche que volvió en sí Altisidora'; y por si no bastara, el narrador - pardon, Sancho- "acomodóle también la coroza en la

${ }^{14}$ Importante el comentario de A. Redondo, "Tradición. . ", pp. 54 ss., sobre este traje y la escena entera, con oportunas llamadas a las "fiestas del asno"' medievales, al parecer todavía vigentes en la Toledo del siglo XVI, según un testigo de la época. El alegato requeriría más averiguaciones porque es muy probable que no se tratara ya del antiguo rito sino más bien de "un reste défiguré" de él, como juzga cierta procesión con el asno protagonista y su bendición que tenía lugar en Madrid los 17 de enero, cf. FÉLIX Clement, Histoire générale de la musique religieuse, Paris, 1861, pp. 181-182; del mismo véase "Drame liturgique. L'âne au moyen âge", Annales Archéologiques, 15 (1855), 373-386 y 16 (1856), 26-38. Sobre 1' office des fous (otro rito medieval con mezcla subversiva de lo sagrado y lo profano) y la prose de l'âne, y fiestas de "locos" y de "asnos" reunidas, véanse DU CANGE, Glossarium ad scriptores mediae et infimae latinitatis..., Paris, 1733, t. 3, s.v. ane, de P. Moncelle, en esp. las cols. 1816-1826; Henry C. Greene, "The song of the Ass Orientis Partibus, with special reference to Edgerton Ms. 2615"', Sp, 6 (1931), 534-549; G. ScALIA, art. cit., pp. 138-147, con abundante bibliografía.

${ }^{15}$ Francisco Márquez Villanueva, Personajes y temas del "Quijote", Taurus, Madrid, 1975, pp. 219-227, pero sin aludir al traje de Sancho. Para otros rasgos de este perfil del escudero, véase Anthony J. Close, "Sancho Panza: Wise fool", MLR, 68 (1973), 344-357. Síntesis de los estudios sobre el personaje y bibliografía en EDUARdo URBINA, "Sancho Panza a nueva luz: ¿tipo folklórico o personaje literario?", ACer, 20 (1982), 93-101. 
cabeza, que fue la más nueva transformación y adorno con que se vio jamás jumento en el mundo"' (II, 73, p. 582). De los cuatro malogrados "héroes", los dos humanos y los dos animales, bien merecía que fuera el menos motivado y el más animal de todos el único que regresa en apariencia de triunfo, como decre$\tan$ los mochachos con su guasona gritería ${ }^{16}$. Pero realmente ese triunfo es sólo apariencia, siendo también el rucio hasta el final hijo de "padrastro": con el llameante sambenito a cuestas y la coroza por refuerzo, parece despedirse encaminado más bien hacia territorios infernales que hacia los cariños de Teresa. Los cuidados de la señora de Panza se concentran ya en el gobierno frustrado y en las monedas sonantes del esposo; para el rucio queda, tirando distraídamente de él, sólo la mano de Sanchica.

Giuseppe Di Stefano

Università di Pisa

${ }^{16} \mathrm{Cf}$. la nota 14 sobre adorno del asno y cortejo. Aduce este personaje y lo pone en relación con el ceremonial del auto de fe por un lado y ritos cuaresmales por otro, Pilar García de Diego, "El testamento en la tradición", RDTP, 9 (1953), 601-666, y 10 (1954), 400-471, en esp. p. 661. Sobre el asno y su variado universo de motivos, símbolos y textos, véase GiUSEPPE FinZI, L'asino nella leggenda e nella letteratura, Modena, 1892; Waldemar Deonna, "Laus asini. L'âne, le serpent, l'eau et l'inmortalité", $R B P H, 34$ (1956), pp. 5-46, 337-364 y 623-658; MARTIN Vogel, Onos lyras, Düsseldorf, 1973; NucCIO ORdine, La cabala dell'asino. Asinità e conoscenza in Giordano Bruno, Liguori, Napoli, 1987, en esp. pp. 16-24, 78-79 y 123-125. Aquí y allá en El Quijote se pueden captar también ligeras resonancias de la laus asini, una especie de género menor cómico-didascálico que tuvo gran éxito en el siglo XVI y en parte del XVir. Para España se suele remitir al "Coloquio cuarto del Porfiado. Segunda parte en la cual se acaba y concluye con una oración de alabanza y loores del asno", de Pero Mexía, Coloquios (1547), Sevilla, 1947, esp. pp. 167178. Pero hay que recordar también las cinco enjundiosas y serias columnas que al asno dedica Sebastián de Covarrubias y Horozco, Tesoro de la lengua castellana o española (Madrid, 1611), ed. Martín de Riquer, Barcelona, 1943, pp. 156-159. 